\title{
Use of Copaifera multijuga for acute corneal repair after chemical injury: A clinical, histopathological and toxicogenetic study
}

\author{
Fernanda Gosuen Gonçalves Dias ${ }^{\mathrm{a}}$, Adriana Torrecilhas Jorge ${ }^{\mathrm{a}}$, Lucas de Freitas Pereira ${ }^{\mathrm{a}}$, \\ Ricardo Andrade Furtado ${ }^{\mathrm{a}}$, Sérgio Ricardo Ambrósio ${ }^{\mathrm{a}}$, Jairo Kenupp Bastos ${ }^{\mathrm{b}}$, \\ Salvador Boccaletti Ramos ${ }^{\mathrm{a}}$, Fernando Chahud ${ }^{\mathrm{b}}$, Luis Gustavo Gosuen Gonçalves Dias ${ }^{\mathrm{c}}$, \\ Cristiane dos Santos Honsho ${ }^{a}$, Denise Crispim Tavares ${ }^{\mathrm{a}, *}$ \\ ${ }^{a}$ University of Franca, Avenida Dr. Armando Salles de Oliveira 201, 14404-600, Franca, São Paulo, Brazil \\ ${ }^{\mathrm{b}}$ School of Pharmaceutical Sciences of Ribeirão Preto, University of São Paulo, Avenida Café s/n, 14040-903, Ribeirão Preto, São Paulo, Brazil \\ ${ }^{\mathrm{c}}$ São Paulo State University, Via de Acesso Prof. Paulo Donato Castelane s/n, 14884-900, Jaboticabal, São Paulo, Brazil
}

\section{A R T I C L E I N F O}

\section{Keywords:}

Copaifera multijuga

Hayne

Ulcerative keratitis

Corneal re-epithelization

Genotoxicity

\begin{abstract}
A B S T R A C T
Copaiba oil is widely used in medicine, but there are no reports regarding its application in ophthalmology. Therefore, the objective of this study was to evaluate the clinical, histopathological and toxicogenetic effects of eye drops containing 0.1 and $0.5 \%$ of Copaifera multijuga Hayne oil on superficial corneal ulcers induced with alkali in the left eye of rats. For histological analysis, the percent reduction in ulcers and thickness of the corneal epithelium and stroma were evaluated 48 and $72 \mathrm{~h}$ after ulcer induction. Additionally, neovascularization and polymorphonuclear infiltration were classified in the stroma. The bone marrow micronucleus test was used for toxicogenetic assessment. None of the animals exhibited clinical signs of immediate ocular discomfort after instillation and the eye drops were harmless to the ocular surface. There was a significant difference in percent ulcer reduction and corneal stroma thickness between animals treated with the $C$. multijuga eye drops and untreated animals with corneal injury and the negative control, respectively, suggesting a healing effect of the oleoresin. Analysis of the thickness of the corneal epithelium at the two time points showed that the eye drops formulated did not significantly reduce the damage caused by alkali. The same was observed for the treatments with the reference drugs. No difference in stromal neovascularization or inflammatory infiltration was observed between the treated groups. The toxicogenetic results revealed the absence of cytotoxicity and genotoxicity of the treatments. In conclusion, the C. multijuga eye drops did not cause damage to the ocular surface under the present experimental conditions and corneal epithelization was similar to the conventional treatments. These results indicate that eye drops containing C. multijuga oleoresin are a promising option for the treatment of superficial keratitis.
\end{abstract}

\section{Introduction}

Superficial corneal ulcers are a common finding because of the constant exposure of the cornea to the environment [1]. Etiological factors include alkali burns, which are an ocular emergency because they cause damage to the surface and anterior segment [2]. Alkaline products penetrate the cornea, causing damaging by the action of hydroxyl ions that promote saponification of triglycerides and cell membrane lysis. Furthermore, $\mathrm{pH}$ changes result in the hydrolysis and denaturation of proteins and enzymes and the consequent loss of cell function and death [3].

Although several therapeutic modalities exist for alkali burns, none of them is completely effective [4]. Thus, new drugs need to be identified, for example natural products that can be used alone or in combination with already established drugs [5]. Within this context, the oleoresin of Copaifera multijuga Hayne is an interesting option because of its documented medicinal effects such as antimicrobial [6], antinociceptive [7], anti-inflammatory [8] and healing properties [9]. These activities are attributed to the presence of sesquiterpene and diterpene metabolites [10].

Since ulcers are a common condition [11] and considering the therapeutic properties of copaiba oil $[7,12,13]$ and the lack of scientific studies on the use of this plant subproduct in ophthalmology, the objective of the present study was to evaluate the topical activity of $C$. multijuga oleoresin in corneal repair and its genotoxic potential.

\footnotetext{
* Corresponding author

E-mail address: denisecrispim2001@yahoo.com (D.C. Tavares).
} 


\section{Material and methods}

\subsection{Collection of the oleoresin of Copaifera multijuga}

The oleoresin was collected in Manacapuru, AM, Brazil (03ํ⒒858' $S$ latitude and $60^{\circ} 35.437^{\prime}$ W longitude). Exsiccates permitted botanical identification (NID: 62/2013) in the Zoological and Botanical Park of the Emílio Goeldi Museum in Belém (PA). The following major compounds were identified by chromatographic analysis: $\beta$-caryophyllene,

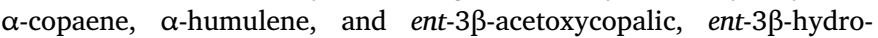
xycopalic and ent-copalic acid.

\subsection{Formulations and preparation of the eye drops}

The low water solubility of the oleoresin impaired its incorporation into an ophthalmic pharmaceutical form and it was necessary to dilute the oil in $5 \%$ Tween $80^{\circ}$ in distilled water. The eye drop solutions were prepared daily at $0.1 \%$ and $0.5 \%$ and no oscillations in $\mathrm{pH}$ or physical stability were observed over a period of $24 \mathrm{~h}$.

\subsection{Animals and chemical induction of corneal ulcers}

Male Wistar rats (Rattus norvegicus), weighing approximately $120 \mathrm{~g}$, were supplied by the Animal House of the School of Pharmaceutical Sciences of Ribeirão Preto, University of São Paulo, Ribeirão Preto (São Paulo, Brazil). The study was conducted in accordance with internationally accepted guidelines for the use and care of laboratory animals. The animals were acclimated for one week before the beginning of the experiments. During the experiments, the animals were kept in plastic boxes in an experimental room under controlled conditions of temperature $\left(22 \pm 2{ }^{\circ} \mathrm{C}\right)$ and humidity $(50 \pm 10 \%)$ under a $12 \mathrm{~h}$ lightdark cycle, with standard rat chow and water available ad libitum. The study protocol was approved by the Animal Care and Use Committee of the University of Franca (Approval No. 051/13).

For standardization and animal welfare, only the left eyes were used [14]. The animals were anesthetized by intraperitoneal administration of ketamine hydrochloride $(50 \mathrm{mg} / \mathrm{kg}$ ) and xylazine hydrochloride (5 mg/kg) [15]. Additionally, 0.5\% proxymetacaine hydrochloride was applied for ocular anesthesia [11]. Ulcers were induced using a 3-mm diameter Whatman No. 41 filter paper disk produced with a surgical punch [4] and immersed in $1 \mathrm{~N}$ sodium hydroxide solution for $15 \mathrm{~s}$ [5]. The disk was then placed in the center of the cornea for one minute and disposed of after use. Corneal debridement was performed with a swab, followed by washing with saline. Ulcer formation was confirmed by staining with $1 \%$ fluorescein sodium.

\subsection{Experimental design}

The rats were divided into 18 groups of six animals each: animals without corneal injury treated with the eye drops containing $0.1 \%$ and $0.5 \%$ C. multijuga oil (CM $0.1 \%$ and CM $0.5 \%$ ) for 48 (T48) or $72 \mathrm{~h}$ (T72); control animals with corneal injury (CI) at T48 and T72; animals with corneal injury treated with $5 \%$ Tween $80^{\circ}$ solvent (IS) at T48 and T72; animals with corneal injury treated with the eye drops containing $0.1 \%$ and $0.5 \%$ C. multijuga oil (ICM $0.1 \%$ and ICM $0.5 \%$ ) at T48 and T72; animals with corneal injury treated with commercial eye drops (IED) at T48 and T72, and animals with corneal injury treated with commercial ointment (IO) at T48 and T72. In addition, negative (no treatment - NC) and methyl methanesulfonate (MMS) $(40 \mathrm{mg} / \mathrm{kg}$ body weight, i.p., single dose) control groups were included in the toxicogenetic assays.

The following commercial ophthalmic drugs commonly used in Brazil were applied as reference: tear-replacing eye drops (Lacrima Plus : $0.1 \%$ dextran 70 and $0.3 \%$ hypromellose) and antibiotic ointment (Epitezan : 10,000 IU retinol acetate, 2.5\% amino acids, 0.5\% methionine, and $0.5 \%$ chloramphenicol).
The eye drop solutions ( 1 drop, $50 \mu \mathrm{L}$ ) and ointment (thin layer) were instilled every $6 \mathrm{~h}$ over the periods established. Tramadol hydrochloride $(5 \mathrm{mg} / \mathrm{kg}$, subcutaneously, every $12 \mathrm{~h}$ ) [15] was administered to all animals, except for the NC and MMS controls, until the end of the study periods. The animals were killed with sodium pentobarbital $(120 \mathrm{mg} / \mathrm{kg}$ body weight, i.p.) $24 \mathrm{~h}$ after the last treatment.

\subsection{Clinical examination}

Local symptoms indicating ocular discomfort after the instillations were evaluated daily by direct inspection and a percentage of symptomatic animals was established for statistical comparison of the results between groups.

Ophthalmological signs were evaluated daily until the end of treatment by clinical examination and direct inspection. Ulcerations in the topically treated groups were confirmed by sodium fluorescein staining. For the evaluation of ulcers in relation to epithelialization, when compared to $\mathrm{T} 0$, the corneas were photographed at T48 or T72 after instillation of sodium fluorescein. The photographs were edited with Photoshop for the elimination of artifacts and were analyzed with the Image $J^{\circ}$ program for automatic quantification of the stained area. After measurement of six random initial areas of the ulcers (T0), measurements were made in the corneal areas of the respective animals to obtain the percentages that these ulcers represented in relation to the corneas. The remaining photographs obtained at T48 or T72 were submitted to the same steps and calculation of percentages for comparison to $\mathrm{T} 0$.

\subsection{Histopathological analysis}

The corneas were obtained by subconjunctival enucleation [2] for the preparation of histological slides [16]. The slides were analyzed under a bright-field microscope for digitalization of the corneal epithelium $(400 \times$ magnification) and stroma $(200 \times)$. Three measurements of the thickness $(\mu \mathrm{m})$ of these layers were obtained with the Image $J^{\circ}$ program in random areas close to the wound and the mean of these measurements was calculated. Six healthy corneas from animals of the negative control group were submitted to the same procedures for statistical comparison with the other groups.

Neovascularization $(200 \times)$ was classified in the stroma close to the wound area as follows: 0 (absent, no new vessels), 1 (mild, up to five blood vessels), 2 (moderate, six to 10 vessels), or 3 (intense, more than 11 vessels). Under an immersion objective $(1,000 \times)$, polymorphonuclear leukocytes were quantified using the same scores considering leukocytes instead of vessels.

\subsection{Toxicogenetic assessment}

The genotoxic and cytotoxic potential was evaluated following the OECD 474 [17] recommendations. For assessment of genotoxicity, 5000 polychromatic erythrocytes (PCEs) were analyzed per animal to obtain the frequency of micronucleated erythrocytes (PCEMNs). For evaluation of cytotoxicity, 500 erythrocytes/animal were analyzed and the ratio of PCEs/total erythrocytes was determined.

\subsection{Statistical analysis}

The results of immediate clinical analysis and those obtained at the end of treatment were submitted to logistic regression, adopting a level of significance of $10 \%$. Ulcer evolution and the histopathological and toxicogenetic results were analyzed by simple analysis of variance (oneway ANOVA) for completely randomized experiments, calculating $\mathrm{F}$ statistics and the respective $P$-value. In the case of $P \leq 0.05$, treatment means were compared by the Tukey test and the least significant difference was calculated for $\alpha=0.05$ (GraphPad Prism 5.0 ${ }^{\circ}$ ). 
Table 1

Percentage of Wistar rats with corneal ulcer and perilesional corneal edema in each group after different times of ophthalmic treatment with Copaifera multijuga oil-containing eye drops or commercial products and their respective controls.

\begin{tabular}{|c|c|c|c|c|c|c|}
\hline \multirow[t]{2}{*}{ Group } & \multicolumn{3}{|c|}{ Corneal ulcer } & \multicolumn{3}{|c|}{ Corneal edema } \\
\hline & $\mathrm{T} 24$ & $\mathrm{~T} 48$ & T72 & $\mathrm{T} 24$ & $\mathrm{~T} 48$ & $\mathrm{~T} 72$ \\
\hline CM $0.1 \%$ & $0 \%$ & $0 \%$ & $0 \%$ & $0 \%$ & $0 \%$ & $0 \%$ \\
\hline CM $0.5 \%$ & $0 \%$ & $0 \%$ & $0 \%$ & $0 \%$ & $0 \%$ & $0 \%$ \\
\hline CI & $100.0 \%$ & $66.7 \%$ & $50.0 \%$ & $100.0 \%$ & $100.0 \%$ & $100.0 \%$ \\
\hline IS & $83.3 \%$ & $14.7 \%$ & $33.3 \%$ & $91.7 \%$ & $83.3 \%$ & $66.7 \%$ \\
\hline ICM $0.1 \%$ & $83.3 \%$ & $25.0 \%$ & $33.3 \%$ & $100.0 \%$ & 100.0 & $83.3 \%$ \\
\hline ICM $0.5 \%$ & $83.3 \%$ & $33.3 \%$ & $50.0 \%$ & $100.0 \%$ & $100.0 \%$ & $100.0 \%$ \\
\hline IED & $91.7 \%$ & $50.0 \%$ & $16.7 \%$ & $100.0 \%$ & $100.0 \%$ & $66.7 \%$ \\
\hline IO & $75.0 \%$ & $25.0 \%$ & $16.7 \%$ & $83.3 \%$ & $75.0 \%$ & $33.3 \%$ \\
\hline
\end{tabular}

T24, T48 and T72: 24,48 and $72 \mathrm{~h}$ of ophthalmic treatment and clinical evaluation, respectively; n: number of animals; $\mathrm{CM} 0.1 \%$ and $0.5 \%$ : animals without corneal injury treated with eye drops containing $0.1 \%$ and $0.5 \%$ copaiba oil, respectively; CI: untreated control with corneal injury; IS: animals with corneal injury treated with $5 \%$ Tween $80^{\circ}$ solvent; ICM $0.1 \%$ and $0.5 \%$ : animals with corneal injury treated with eye drops containing $0.1 \%$ and $0.5 \%$ C. multijuga oleoresin, respectively; IED: animals with corneal injury treated with commercial eye drops; IO: animals with corneal injury treated with commercial ointment.

\section{Results}

\subsection{Clinical data}

Sodium hydroxide induced the formation of corneal ulcers and perilesional edema. Immediate clinical analysis revealed no ocular discomfort after the instillations in any of the animals, and no difference was observed between groups or treatment times.

The signs observed at the end of the treatments were corneal ulcers and perilesional corneal edema (Table 1). However, no signs were found for the CM $0.1 \%$ and $\mathrm{CM} 0.5 \%$ groups, demonstrating that the oleoresin was harmless to the ocular surface.

A reduction in the number of animals with a positive fluorescein test was observed in the ICM $0.1 \%$ and ICM $0.5 \%$ groups compared to CI, suggesting re-epithelization and a consequent healing effect of the oleoresin. However, the ulcers persisted until the last assessment in all groups with corneal injury, including those treated with the commercial products. Although a decrease in the number of animals with corneal ulcers was observed in the IS group, more marked percent reductions were found in the ICM $0.1 \%$ and ICM $0.5 \%$ groups at T48.

Regarding corneal edema, the group ICM $0.1 \%$ was less affected at T72 than CI, indicating an anti-inflammatory activity of the oil.

Table 2 shows the percent reduction in corneal ulcers. All groups exhibited significant reductions at T48 and T72 compared to T0. In addition, statistically significant reductions in corneal ulcers were observed

Table 2

Percent reduction in left corneal ulcers of Wistar rats treated with eye drops containing Copaifera multijuga oleoresin or commercial products and their respective controls.

\begin{tabular}{|c|c|c|}
\hline Group & $\mathrm{T} 48$ & $\mathrm{~T} 72$ \\
\hline CI & $67.1 \%$ * & $84.3 \%$ * \\
\hline IS & $98.8 \%$ *, & $92.6 \%{ }^{*}$ \\
\hline ICM $0.1 \%$ & $100.0 \%$ & $92.3 \%$ \\
\hline ICM $0.5 \%$ & $97.7 \%$ *,** & $63.9 \%{ }^{*}$ \\
\hline IED & $81.4 \%^{n, k * k}$ & $100.0 \%$ " \\
\hline IO & $100.0 \%$ & $97.6 \%$ \\
\hline
\end{tabular}

T48: $48 \mathrm{~h}$ of treatment; T72: $72 \mathrm{~h}$ of treatment; CI: untreated control with corneal injury; IS: animals with corneal injury treated with $5 \%$ Tween $80^{\circ}$ solvent; ICM $0.1 \%$ and $0.5 \%$ : animals with corneal injury treated with eye drops containing $0.1 \%$ and $0.5 \%$ C. multijuga oleoresin, respectively; IED: animals with corneal injury treated with commercial eye drops; IO: animals with corneal injury treated with commercial ointment.

* Significantly different from T0 (before treatment) $(\mathrm{P}<0.05)$.

** Significantly different from CI $(\mathrm{P}<0.05)$.
T48

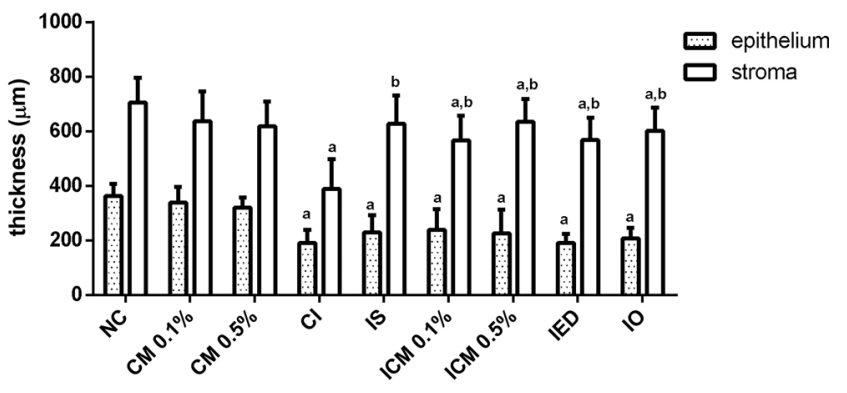

T72

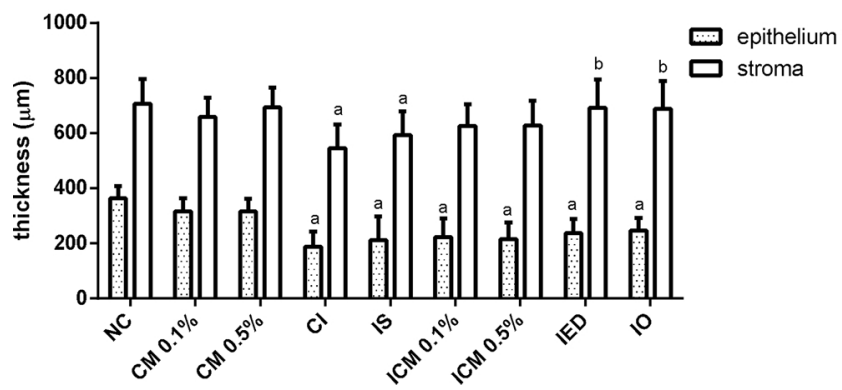

Fig. 1. Thickness of the epithelium and stroma of the left cornea of Wistar rats treated for $48 \mathrm{~h}$ (T48) and $72 \mathrm{~h}$ (T72) with eye drops containing Copaifera multijuga Hayne oil or commercial products and their respective controls.

NC: negative control (animals without corneal injury not submitted to topical treatment); CM $0.1 \%$ and $0.5 \%$ : animals without corneal injury treated with eye drops containing $0.1 \%$ and $0.5 \%$ copaiba oil, respectively; CI: untreated control animals with corneal injury; IS: animals with corneal injury treated with $5 \%$ Tween $80^{\circ}$ solvent; ICM $0.1 \%$ and $0.5 \%$ : animals with corneal injury treated with eye drops containing $0.1 \%$ and $0.5 \%$ copaiba oil, respectively; IED: animals with corneal injury treated with commercial Lacrima Plus eye drops; IO: animals with corneal injury treated with commercial Epitezan" ointment.

a Significantly different from NC $(P<0.05)$

${ }^{\mathrm{b}}$ Significantly different from CI $(P<0.05)$.

at T48 in the groups treated with $C$. multijuga eye drops and with the commercial products when compared to the untreated control group.

\subsection{Histopathological results}

When compared to the NC group, treatment with the $C$. multijuga eye drops did not reduce the damage to the corneal epithelium caused by alkali at T48 or T72. The same was observed for the other groups, including those treated with the commercial products. On the other hand, the $C$. multijuga eye drops significantly increased stromal thickness at T48 when compared to the CI group, demonstrating the healing properties of the oleoresin. Similar effects were found for the commercial eye drops and ointment. At T72, a reduction in stromal damage was observed in the groups treated with the $C$. multijuga eye drops compared to the CI group, but the difference was not statistically significant. There were also no significant differences compared to the NC group (Fig. 1).

Neovascularization did not differ significantly between the treatment groups and the NC group at either time point analyzed (Table 3). Inflammatory infiltration in the damaged cornea was significantly increased in the groups with injury at T48 and T72 compared to the NC group, a finding favoring the removal of cell debris and defense against microorganisms. Animals with injury treated with the $C$. multijuga eye drops and commercial drugs did not differ from the CI group (Table 3).

More intense cytoplasmic vacuolization of the corneal epithelium was observed at T48 in animals of the CI, IS, ICM $0.5 \%$ and IED groups (Fig. 2A). Lacunae among stromal collagen fibers were noted in all groups with corneal injury (Fig. 2B). 
Table 3

Scores of neovascularization and inflammatory infiltrate in the left corneal stroma of Wistar rats treated for 48 or $72 \mathrm{~h}$ with eye drops containing Copaifera multijuga oleoresin or commercial products and their respective controls.

\begin{tabular}{llllll}
\hline \multirow{2}{*}{ Group } & \multicolumn{2}{l}{ T48 } & & \multicolumn{2}{l}{ T72 } \\
\cline { 2 - 3 } \cline { 5 - 6 } & New vessels & $\begin{array}{l}\text { Inflammatory } \\
\text { infiltrate }\end{array}$ & & New vessels & $\begin{array}{l}\text { Inflammatory } \\
\text { infiltrate }\end{array}$ \\
\hline NC & $0.17 \pm 0.41$ & $0.17 \pm 0.41$ & & $0.17 \pm 0.41$ & $0.17 \pm 0.41$ \\
CM 0.1\% & 0 & $0.17 \pm 0.41$ & & $0.33 \pm 0.52$ \\
CM 0.5\% & 0 & $0.50 \pm 0.55$ & & 0 & $0.50 \pm 0.55$ \\
CI & $0.50 \pm 0.84$ & $2.67 \pm 0.82^{*}$ & & $1.83 \pm 1.47$ & $2.33 \pm 0.82^{*}$ \\
IS & $1.00 \pm 1.10$ & $2.67 \pm 0.52^{*}$ & & $1.17 \pm 1.47$ & $2.33 \pm 0.82^{*}$ \\
ICM 0.1\% & $0.33 \pm 0.52$ & $2.67 \pm 0.82^{*}$ & & $0.83 \pm 0.75$ & $2.50 \pm 0.55^{*}$ \\
ICM 0.5\% & $0.50 \pm 0.55$ & $2.17 \pm 0.98^{*}$ & & $1.17 \pm 0.98$ & $2.17 \pm 0.98^{*}$ \\
IED & $0.83 \pm 1.17$ & $2.67 \pm 0.52^{*}$ & & $1.67 \pm 1.21$ & $2.17 \pm 0.75^{*}$ \\
IO & $0.67 \pm 0.82$ & $1.83 \pm 0.75^{*}$ & & $1.00 \pm 0.89$ & $1.50 \pm 0.55^{*}$ \\
\hline
\end{tabular}

T48: $48 \mathrm{~h}$ of treatment; T72: $72 \mathrm{~h}$ of treatment; NC: animals without corneal injury not submitted to treatment (negative control); $\mathrm{CM} 0.1 \%$ and $0.5 \%$ : animals without corneal injury treated with eye drops containing $0.1 \%$ and $0.5 \%$ copaiba oil, respectively; CI: untreated control with corneal injury; IS: animals with corneal injury treated with $5 \%$ Tween $80^{\circ}$ solvent; ICM $0.1 \%$ and $0.5 \%$ : animals with corneal injury treated with eye drops containing $0.1 \%$ and $0.5 \%$ C. multijuga oleoresin, respectively; IED: animals with corneal injury treated with commercial eye drops; IO: animals with corneal injury treated with commercial ointment.

Values are the mean \pm standard deviation.

* Significantly different from NC $(P<0.05)$.

\subsection{Toxicogenetic assessment}

No significant differences in the frequency of PCEMNs or in the PCE/total erythrocyte ratio were observed between the treatment groups and the NC group, demonstrating the absence of genotoxicity and cytotoxicity at the time points studied (Table 4).

\section{Discussion}

Chemical analysis of the copaiba oil used in the present study permitted to determine its chromatographic profile, ensuring credibility of the study. According to Veiga et al. [13], the price difference to other oils renders adulteration common, a process that reduces effectiveness of the active ingredients and generates disbelief in the pharmacological efficacy of the product. Scientific studies have identified diterpenes and sesquiterpenes as major compounds of the oleoresin [1-19]. Since these compounds account for more than $90 \%$ of the composition of $C$. multijuga oil, its pharmacological activities can be attributed to these molecules [20].

The model of iatrogenic induction of ulcers with filter paper was based on the experiments of [21] and [22]. Standardization of disk size and thickness and permanence on the corneal surface [23] minimized differences in depth, ensuring uniformity of the ulcers. The ulcers were induced in the center of the cornea to avoid damage to the limbus and its stem cells and consequent impairment of cell migration and healing [24]. Furthermore, the sensitivity threshold is higher in the center of the cornea because of extensive neuronal density [25], a fact contributing to the investigation of new ophthalmic products, especially those related to nociceptive analysis and local irritation.

The pharmaceutical form was chosen because of its easy instillation and to prevent wasting during the applications [11]. Since this is the first study using $C$. multijuga oleoresin to treat superficial keratitis, it was necessary to test different concentrations of the solutions in a pilot study. In that analysis, concentrations of the eye drop solution of 1,3 and $5 \%$ were found to predispose to hyphema, flare and fibrin accumulation in the anterior chamber of most of the treated eyes and were therefore unsuitable to study the effect of the oleoresin on superficial keratitis.

The interval between instillations was based on the demonstration that frequent applications result in higher local concentrations [26] and that lacrimal drainage causes the rapid loss of the instilled ophthalmic solution [27]. In this respect, the greater the viscosity of the drug, the more difficult its removal from the corneal surface. Despite the viscosity of the $C$. multijuga oleoresin, it was not instilled without previous dilution because its natural $\mathrm{pH}$ is acid $(\mathrm{pH} 4.2)$, a fact that can cause iatrogenic injury and compromise ocular homeostasis. The concentration of the vehicle was defined so that its amount was sufficient to dilute the oil.

The similar clinical (corneal re-epithelization) and histopathological results (stromal healing demonstrated by the thickness of this corneal layer, neovascularization and inflammatory infiltrate) obtained for animals with injury treated with the solvent and with the $C$. multijuga eye drops suggest that the solvent may have interfered with the action the oleoresin exerted on the ulcers. The lowest concentration possible of the solvent was used for solubilization of the oleoresin to permit dilution and preparation of the eye drops. The biological effects may be attributed in part to the interaction between substances of the oleoresin and solvent [28]. Furthermore, the viscosity and surfactant, hydrophilic and tensoactive characteristics of the solvent [1] probably reduced superficial ocular tension and thus permitted better contact with the lacrimal film and improvement in corneal lubrication, favoring cell migration adjacent to the wound margin [29].

The full acceptance of the commercial pomade used in the present study is attributed to its viscosity and composition, particularly retinol acetate which is essential for epithelial repair and maintenance, and chloramphenicol which exerts intraocular antibiotic activity. The commercial eye drops were adopted to stabilize the lacrimal film and to reduce its fragmentation time in cases in which the loss due to evaporation is increased [26]. Despite a different composition, the commercial products used in the present study did not differ in terms of percent ulcer reduction, restoration of epithelial thickness, neovascularization or inflammatory infiltrate. Both products exhibited effects similar those observed for the treatments with the C. multijuga oilcontaining eye drops.

The gradual decrease in corneal edema observed in animals treated

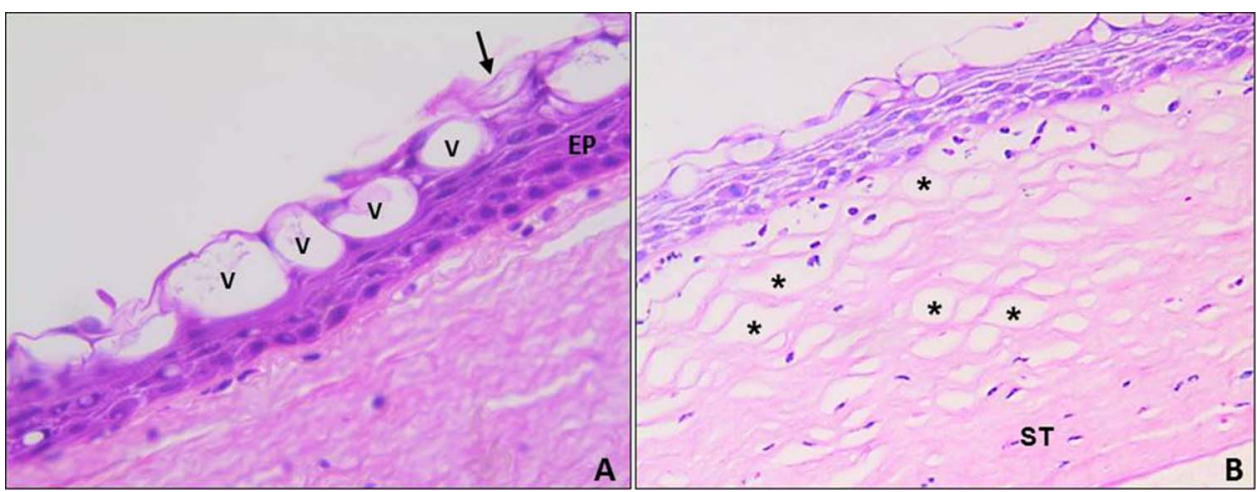

Fig. 2. Digital photomicrographs of the cornea of Wistar rats. A - Cytoplasmic vacuolization (V) of the corneal epithelium (EP) observed in all groups with corneal ulcers at $48 \mathrm{~h}$ after induction with alkali (H.E., $400 \times$ ), associated with alterations in the structural quality of this newly formed layer (arrow). B - Corneal injury after $48 \mathrm{~h}$. Observe the lacunae (*) among stromal collagen fibers (ST) (H.E., 200×). 
Table 4

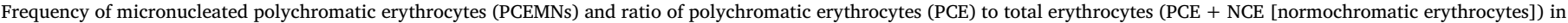
bone marrow of Wistar rats treated for 48 or $72 \mathrm{~h}$ with eye drops containing Copaifera multijuga oleoresin or commercial products and their respective controls.

\begin{tabular}{|c|c|c|c|c|}
\hline \multirow[t]{2}{*}{ Group } & \multicolumn{2}{|l|}{$\mathrm{T} 48$} & \multicolumn{2}{|l|}{ T72 } \\
\hline & PCEMNs & PCE/PCE + NCE & PCEMNs & PCE/PCE + NCE \\
\hline $\mathrm{NC}$ & $11.00 \pm 3.85$ & $0.65 \pm 0.10$ & $11.00 \pm 3.85$ & $0.65 \pm 0.10$ \\
\hline CM $0.1 \%$ & $10.83 \pm 4.12$ & $0.67 \pm 0.07$ & $11.67 \pm 4.12$ & $0.67 \pm 0.03$ \\
\hline CM $0.5 \%$ & $14.83 \pm 1.83$ & $0.65 \pm 0.08$ & $12.83 \pm 1.83$ & $0.67 \pm 0.07$ \\
\hline $\mathrm{CI}$ & $11.83 \pm 1.94$ & $0.62 \pm 0.07$ & $10.50 \pm 1.94$ & $0.60 \pm 0.02$ \\
\hline IS & $12.17 \pm 1.33$ & $0.65 \pm 0.05$ & $9.33 \pm 1.33$ & $0.67 \pm 0.02$ \\
\hline ICM $0.1 \%$ & $12.50 \pm 2.17$ & $0.65 \pm 0.08$ & $12.50 \pm 2.17$ & $0.73 \pm 0.03$ \\
\hline ICM $0.5 \%$ & $12.50 \pm 2.88$ & $0.67 \pm 0.05$ & $11.83 \pm 2.88$ & $0.68 \pm 0.05$ \\
\hline IED & $10.00 \pm 2.28$ & $0.71 \pm 0.04$ & $10.00 \pm 2.28$ & $0.71 \pm 0.03$ \\
\hline IO & $10.67 \pm 1.97$ & $0.71 \pm 0.05$ & $10.00 \pm 1.97$ & $0.70 \pm 0.05$ \\
\hline MMS & $92.50 \pm 17.68^{*}$ & $0.44 \pm 0.01^{*}$ & $92.50 \pm 17.68$ & $0.44 \pm 0.01^{*}$ \\
\hline
\end{tabular}

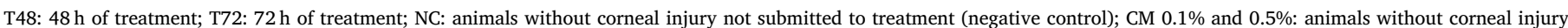

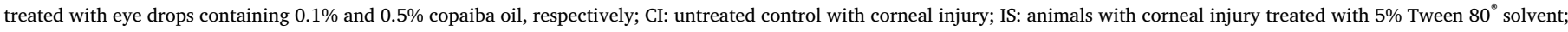

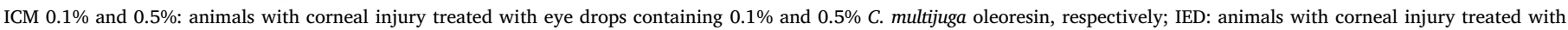
commercial eye drops; IO: animals with corneal injury treated with commercial ointment; MMS: methyl methanesulfonate control.

Values are the mean \pm standard deviation.

The frequency of PCEMNs was obtained analyzing 5000 PCEs/animal.

The PCE/PCE + NCE ratio was calculated analyzing 500 erythrocytes/animal.

* Significantly different from NC $(P<0.001)$.

with $0.1 \%$ C. multijuga eye drops at T72 was probably due to organization of stromal collagen fibers [3] mediated by the anti-inflammatory effect of this oleoresin. According to Veiga et al. [13], this anti-inflammatory effect can be attributed to the presence of sesquiterpenes, especially $\beta$-caryophyllene, a molecule found at high concentrations in the oil used in the present experiment.

The absence of ocular secretion in the treated groups can be explained by the lack of conjunctival and corneal irritation [11], as well as by the probable microbiological control exerted by the $C$. multijuga oleoresin at the concentrations tested. The antimicrobial effect of this oil has been demonstrated in vitro by Mendonça and Onofre [6] against some microorganisms such as Pseudomonas aeruginosa, a bacterium that is potentially pathogenic to damaged ocular tissues.

The restoration of corneal epithelial thickness is directly related to inflammatory intensity and to cell proliferation and migration [2], as well as to repair of the stroma which provides the structure for epithelial adherence [11]. Analysis of corneal re-epithelization in the groups treated with the $C$. multijuga eye drops revealed that the copaiba oil did not interfere with the proliferation or transport of cells close to the wound. Similar findings have been reported by Atiba et al. [4]. who used Aloe vera in rats. However, in the present study renewal of the epithelium did not accelerate complete healing, with a difference in epithelial thickness compared to the negative control. This finding might be explained by the short duration of treatment since the epithelium requires $2-10$ days for complete healing, as well as by extensive cytoplasmic vacuolization [30].

Cytoplasmic vacuolization suggests early injuries to epithelial cells by the expulsion of damaged organelles attributed to the hydrophobic interface between water and lipids in the cell cytoplasm, as demonstrated by Zachary and McGavin [30]. Since no cytoplasmic vacuolization was observed in animals without ulcerations, it is believed that these vacuoles were caused by alkali. The latter induces saponification of triglycerides in the cell membrane [3], compromising the structural quality of the newly formed epithelium because of incomplete restoration of intercellular links [2] and facilitating removal of the epithelium. Closure of the degraded region of the cornea, even with a thin layer of epithelium, possibly prevented the aggravation of corneal edema and limited the access of infectious agents that could hinder and further delay the repair process [30].

The $C$. multijuga eye drops stimulated the proliferation of keratocytes and the production of fibroblasts by favoring stromal repair. This healing property might be attributed to the presence of terpenoids [31], which regulate collagenases [32]. The irregularity of the newly formed stroma seen in the present study, which was characterized by spacing between collagen fibers and incomplete adherence to the epithelium, might be due to edema and degradation of the stromal matrix, as well as deficiency in fibronectin and other adhesion molecules [30]. Another explanation could be the lack of restoration of the tensile strength of this layer, probably due to the short time since injury [11], although the formation of new vessels and migration of leukocytes occurred within the first $48 \mathrm{~h}$ after injury induction. Leukocytes actively participate in tissue organization [2].

At the beginning of the repair process, within the first $48 \mathrm{~h}$ after alkali burn, migration of polymorphonuclear cells to the denuded region of the cornea was observed in all groups with corneal injury, in agreement with the literature [14]. These results confirm that, at the concentrations tested, the oleoresin of $C$. multijuga does not prevent the migration of inflammatory cells during this phase. Similar results have been reported by Martin et al. [2]. who tested the application of green propolis to the cornea of rats. The components of the inflammatory infiltrate stimulate fibroblasts to produce collagen, in agreement with the histological results of stromal thickness. In addition, they secrete cytokines that act on cells residing in the wound, organizing the interactive cellular network during healing [2].

In view of their complexity and severity, the treatment of chemical ulcers continues to be a challenge. In this respect, the present results agree with the report of [33] that, although different therapeutic modalities administered by different routes have been established and tested, none of them is completely effective in mediating corneal healing.

The copaiba oil has not yet been registered as a phytochemical drug. Thus, in the present study, toxicogenetic assays were necessary to verify possible deleterious effects on organs that were not targets of the study [34]. The micronucleus test revealed no structural or numerical chromosome damage in dividing cells of animals treated with C. multijuga oil-containing eye drops, which would therefore not predispose to the occurrence of genetic diseases or neoplasms in exposed individuals. The micronucleus test was used because it is a rapid and simple method of easy interpretation and wide applicability that is less subjective than other mutagenicity assays and provides reliable results after acute treatment. In addition, the micronucleus test is accepted by international agencies and government institutions for registration of new pharmaceutical products [17]. Although Kirsch-Volders et al. [35] showed that the anucleated immature erythrocyte has a short lifespan 
and any micronucleus found is therefore the result of recently induced chromosome damage, young rats were chosen to reduce interferences from preexisting mutagenic environmental factors.

Almeida et al. [36]. used the liver comet assay and peripheral blood and bone marrow micronucleus tests to investigate the acute genotoxic potential of a single administration to mice of copaiba oil by gavage at doses of 500, 1000 and $2000 \mathrm{mg} / \mathrm{kg}$ and observed no cytotoxic or genotoxic effect. Furthermore, Gonçalves et al. [34] demonstrated that the oral administration of C. multijuga oleoresin (200, 500 and $2500 \mathrm{mg} / \mathrm{kg}$, for 8 consecutive weeks) exerted no toxic effect on the reproductive system of male rats.

In conclusion, the eye drops formulated with $C$. multijuga oil were well tolerated by the ocular surface, reduced the symptoms associated with chemically induced corneal ulcers, and showed no cytotoxicity or genotoxicity. In addition, these eye drops mediated corneal re-epithelization similar to that found for the conventional reference products and could be a promising and less costly option for the treatment of chemical superficial keratitis.

\section{Funding}

This work was supported by the São Paulo Research Foundation (grant \#2011/13630-7, FAPESP, Brazil). The authors are grateful to Conselho Nacional de Desenvolvimento Científico e Tecnológico (CNPq) for the fellowships granted.

\section{References}

[1] C.S. Perches, C.V.S. Brandão, J.J.T. Ranzani, C.H. Pellizon, C. Donatti, J.F. Fonzar, M.G. Sereno, G.T. Angélico, C.R. Padovani, Uso do colírio de Citrus lemon em úlceras de córnea induzidas em coelhos, Arq. Bras. Med. Vet. Zootec. 64 (2012) 1161-1168, http://dx.doi.org/10.1590/S0102-09352012000500012.

[2] L.F.T. Martin, E.M. Rocha, S.B. Garcia, J.S. Paula, Topical Brazilian propolis improves corneal wound healing and inflammation in rats following alkali burns, BMC Complement. Altern. Med. (2013), http://dx.doi.org/10.1186/1472-6882-13-337.

[3] C. Busse, C. Hartley, C. Kafarnik, M. Pivetta, Ocular alkaline injury in four dogs presentation, treatment, and follow-up-a case series, Vet. Ophthalmol. 18 (2015) 127-134, http://dx.doi.org/10.1111/vop.12171.

[4] A. Atiba, T. Wasfy, A. Ghoniem, W. Abdo, T. Zayed, M. Shokre, Aloe vera gel facilitates re-epithelialization of corneal alkali burn in normal and diabetic rats, Clin. Ophthalmol. (2015) 2019, http://dx.doi.org/10.2147/OPTH.S90778.

[5] E. Beyazyildiz, F.A. Pinarli, O. Beyazyildiz, U. Beden, T. Delibasi, A modified rat model for corneal alkali burn, Niche J. 1 (2013) 31-33, http://dx.doi.org/10.5152/ niche.2012.07.

[6] D.E. Mendonça, S.B. Onofre, Antimicrobial activity of the oil-resin produced by copaiba Copaifera multijuga Hayne (Leguminosae), Rev. Bras. Farmacogn. 19 (2009) 577-581, http://dx.doi.org/10.1590/S0102-695X2009000400012.

[7] N. de M. Gomes, C.M. de Rezende, S.P. Fontes, M.E. Matheus, A. da, C. Pinto, P.D. Fernandes, Characterization of the antinociceptive and anti-inflammatory activities of fractions obtained from Copaifera multijuga Hayne, J. Ethnopharmacol. 128 (2010) 177-183, http://dx.doi.org/10.1016/j.jep.2010.01.005.

[8] C. Kobayashi, T.O. Fontanive, B.G. Enzweiler, L.R. de Bona, T. Massoni, M.A. Apel, A.T. Henriques, M.F. Richter, P. Ardenghi, E.S. Suyenaga, Pharmacological evaluation of Copaifera multijuga oil in rats, Pharm. Biol. 49 (2011) 306-313, http:// dx.doi.org/10.3109/13880209.2010.515595.

[9] E. de, O. Nogueira, A.S.M. Novaes, C.M.S. Sanchez, C. de M. Andrade, M.F.A. da Silva, Avaliação do efeito do óleo-resina de copaíba (Copaifera sp.) na proliferação celular in vitro, Braz. J. Vet. Res. Anim. Sci. 49 (2012) 293-300, http://dx.doi.org/ 10.11606/issn.1678-4456.v49i4p293-300.

[10] C.L. Morelli, M. Mahrous, M.N. Belgacem, M.C. Branciforti, R.E.S. Bretas, J. Bras, Natural copaiba oil as antibacterial agent for bio-based active packaging, Ind. Crops Prod. 70 (2015) 134-141, http://dx.doi.org/10.1016/j.indcrop.2015.03.036.

[11] K.N. Gelatt, B.C. Gilger, T.J. Kem, Veterinary Ophthalmology, fifth ed., (2013) United States.

[12] H. Liu, G. Yang, Y. Tang, D. Cao, T. Qi, Y. Qi, G. Fan, Physicochemical characterization and pharmacokinetics evaluation of $\beta$-caryophyllene/ $\beta$-cyclodextrin inclusion complex, Int. J. Pharm. 450 (2013) 304-310, http://dx.doi.org/10.1016/j. ijpharm.2013.04.013.

[13] V.F. Veiga, E.C. Rosas, M.V. Carvalho, M.G.M.O. Henriques, A.C. Pinto, Chemical composition and anti-inflammatory activity of copaiba oils from Copaifera cearensis Huber ex Ducke, Copaifera reticulata Ducke and Copaifera multijuga Hayne-a comparative study, J. Ethnopharmacol. 112 (2007) 248-254, http://dx.doi.org/10. 1016/j.jep.2007.03.005.

[14] L.C. Figueroa-Ortiz, O. Martín Rodríguez, A. García-Ben, J. García-Campos, Neovascular growth in an experimental alkali corneal burn model, Arch. Soc. Esp.
Oftalmol. Engl. Ed. (n.d.) 303-307. doi:https://doi.org/10.1016/j.oftale.2014.08. 012.

[15] P.A. Flecknell, C.A. Richardson, A. Popovic, Veterinary Anesthesia and Analgesia, fourth ed., (2007) Iowa.

[16] F.L. Carson, C. Hladik, Histotechnology-A Self Instructional Text, third ed., (2009) Chicago.

[17] OECD, Test No. 474: Mammalian Erythrocyte Micronucleus Test, Organisation for Economic Co-operation and Development, Paris, 2016 (Accessed 21 August 2017), http://www.oecd-ilibrary.org/content/book/9789264264762-en.

[18] L.M. Leandro, F. de Sousa Vargas, P.C.S. Barbosa, J.K.O. Neves, J.A. da Silva, V.F. da Veiga-Junior, Chemistry and biological activities of terpenoids from Copaiba (Copaifera spp.) Oleoresins, Molecules 17 (2012) 3866-3889, http://dx doi.org/10.3390/molecules17043866.

[19] L.G. Lucca, S.P. de Matos, B.T. Borille, D. de, O. Dias, H.F. Teixeira, V.F. Veiga, R.P. Limberger, L.S. Koester, Determination of $\beta$-caryophyllene skin permeation retention from crude copaiba oil (Copaifera multijuga Hayne) and respective oilbased nanoemulsion using a novel HS-GC/MS method, J. Pharm. Biomed. Anal. 104 (2015) 144-148, http://dx.doi.org/10.1016/j.jpba.2014.11.013.

[20] R. de Almeida Vaucher, J.L. Giongo, L.P. Bolzan, M.S. Côrrea, V.P. Fausto, C.F. dos S. Alves, L.Q.S. Lopes, A.A. Boligon, M.L. Athayde, A.P. Moreira, A. Brandelli, R.P. Raffin, R.C.V. Santos, Antimicrobial activity of nanostructured Amazonian oils against Paenibacillus species and their toxicity on larvae and adult worker bees, J. Asia-Pac. Entomol. 18 (2015) 205-210, http://dx.doi.org/10.1016/j.aspen.2015. 01.004.

[21] D.Y. Piso, A.P. Ribeiro, M.L. Silva, P.J. Guimarães, A. Morales, B.C. Martins, I.M. Padua, R. Renzo, A.L. Andrade, R.R. Uscátegui, J.L. Laus, Effects of antiproteolytic agents on corneal epithelial viability and matrix metalloproteinase-2 and metalloproteinase- 9 activity in alkali-burned corneas of rats, Vet. Ophthalmol. 17 (2014) 23-31, http://dx.doi.org/10.1111/vop.12032.

[22] C.-C. Hsu, H.-M. Chang, T.-C. Lin, K.-H. Hung, K.-H. Chien, S.-Y. Chen, S.-N. Chen, Y.-T. Chen, Corneal neovascularization and contemporary antiangiogenic therapeutics, J. Chin. Med. Assoc. 78 (2015) 323-330, http://dx.doi.org/10.1016/j. jcma.2014.10.002.

[23] J. Yamada, M. Reza Dana, C. Sotozono, S. Kinoshita, Local suppression of IL-1 by receptor antagonist in the rat model of corneal alkali injury, Exp. Eye Res. 76 (2003) 161-167, http://dx.doi.org/10.1016/S0014-4835(02)00293-2.

[24] J.R. da, S. Ricardo, J.A.P. Gomes, Use of stem cells cultured ex vivo for ocular surface reconstruction, Arq. Bras. Oftalmol. 73 (2010) 541-547, http://dx.doi.org/ 10.1590/S0004-27492010000600017.

[25] L.J. Müller, C.F. Marfurt, F. Kruse, T.M.T. Tervo, Corneal nerves: structure, contents and function, Exp. Eye Res. 76 (2003) 521-542, http://dx.doi.org/10.1016/S00144835(03)00050-2.

[26] D.J. Maggs, P.E. Miller, R. Ofri, Slatter's Fundamentals of Veterinary Ophthalmology, fifth ed., (2013) St Louis.

[27] A.M. Durrani, S.J. Farr, I.W. Kellaway, Influence of molecular weight and formulation $\mathrm{pH}$ on the precorneal clearance rate of hyaluronic acid in the rabbit eye, Int. J. Pharm. 118 (1995) 243-250, http://dx.doi.org/10.1016/0378-5173(94) 00389-M.

[28] A. Gomez-Lopez, A. Aberkane, E. Petrikkou, E. Mellado, J.L. Rodriguez-Tudela, M. Cuenca-Estrella, Analysis of the influence of Tween concentration, inoculum size, assay medium, and Reading time on susceptibility testing of Aspergillus spp, J. Clin. Microbiol. 43 (2005) 1251-1255, http://dx.doi.org/10.1128/JCM.43.3.12511255.2005 .

[29] A.A.M. Torricelli, S.E. Wilson, Cellular and extracellular matrix modulation of corneal stromal opacity, Exp. Eye Res. 129 (2014) 151-160, http://dx.doi.org/10. 1016/j.exer.2014.09.013.

[30] J.F. Zachary, M.D. McGavin, Bases da Patologia em Veterinária, fifth ed., (2013) Rio de Janeiro.

[31] B.H.I. Ruszymah, S.R. Chowdhury, N.A.B.A. Manan, O.S. Fong, M.I. Adenan, A.B. Saim, Aqueous extract of Centella asiatica promotes corneal epithelium wound healing in vitro, J. Ethnopharmacol. 140 (2012) 333-338, http://dx.doi.org/10. 1016/j.jep.2012.01.023

[32] E.M. Curto, A. Labelle, H.L. Chandler, Aloe vera: an in vitro study of effects on corneal wound closure and collagenase activity, Vet. Ophthalmol. 17 (2014) 403-410, http://dx.doi.org/10.1111/vop.12163.

[33] N. Tuncel, N. Yildirim, F. Gurer, H. Basmak, K. Uzuner, V. Sahinturk, H. Gursoy, Effect of vasoactive intestinal peptide on the wound healing of alkali-burned corneas, Int. J. Ophthalmol. 9 (2016) 204-210, http://dx.doi.org/10.18240/ijo.2016. 02.04 .

[34] E.S. Gonçalves, J.R. Silva, C.L. Gomes, M.B.L. Nery, D.M.A.F. Navarro, G.K.N. Santos, J.C. Silva-Neto, J.H. Costa-Silva, A.V. Araújo, A.G. Wanderley, E.S. Gonçalves, J.R. Silva, C.L. Gomes, M.B.L. Nery, D.M.A.F. Navarro, G.K.N. Santos, J.C. Silva-Neto, J.H. Costa-Silva, A.V. Araújo, A.G. Wanderley, Effects of the oral treatment with Copaifera multijuga oil on reproductive performance of male Wistar rats, Rev. Bras. Farmacogn. 24 (2014) 355-362, http://dx. doi.org/10.1016/j.bjp.2014.07.014.

[35] M. Kirsch-Volders, G. Plas, A. Elhajouji, M. Lukamowicz, L. Gonzalez, K.V. Loock, I. Decordier, The in vitro MN assay in 2011: origin and fate, biological significance, protocols, high throughput methodologies and toxicological relevance, Arch. Toxicol. 85 (2011) 873-899, http://dx.doi.org/10.1007/s00204-011-0691-4.

[36] M.R. Almeida, J.D.C. Darin, L.C. Hernandes, M.F. de Souza Ramos, L.M.G. Antunes, O. de Freitas, Genotoxicity assessment of Copaiba oil and its fractions in Swiss mice, Genet. Mol. Biol. 35 (2012) 664-672, http://dx.doi.org/10.1590/S141547572012005000052 